\title{
An Evaluation on Publicness of Urban Public Spaces by Using Core Dimensions; Specific Reference to Galle Fort (Sea Bath Area), Forest (Beach) Park Area, Mahamodara Marine Walk and Ocean Pathway in Galle
}

\author{
Thilini Bhagya Sandaruwani, Chamali Hewawasam \\ Department of Town \& Country Planning, Faculty of Architecture, University of Moratuwa, Moratuwa, Sri Lanka \\ Email: thilinisandharuwani@gmail.com,chamalih@uom.lk
}

How to cite this paper: Sandaruwani, T. B., \& Hewawasam, C. (2021). An Evaluation on Publicness of Urban Public Spaces by Using Core Dimensions; Specific Reference to Galle Fort (Sea Bath Area), Forest (Beach) Park Area, Mahamodara Marine Walk and Ocean Pathway in Galle. Journal of Service Science and Management, 14, 663-679.

https://doi.org/10.4236/jssm.2021.146042

Received: November 4, 2021

Accepted: December 26, 2021

Published: December 29, 2021

Copyright $\odot 2021$ by author(s) and Scientific Research Publishing Inc. This work is licensed under the Creative Commons Attribution International License (CC BY 4.0).

http://creativecommons.org/licenses/by/4.0/

\section{(c) (i) Open Access}

\begin{abstract}
This paper aims to evaluate the publicness level in publicly owned and managed urban public spaces. For fulfillment of its main objective, this paper firstly examines deeply in existence publicness literatures. In the second part, with aim of finding appropriate model through previous models, and represents a democratic evaluation through a multi-criteria decision-making model. It aims to effectively evaluate and compare the publicness level of public spaces. The selected model assesses the publicness level by using ownership, management, access and user/s dimensions by analyzing the leading dissertations. Evaluating by people has a definite benefit due to good experience and better knowledge of societies about their living environment. The third part draws the research methodology and the final part examines the findings of the case study in Galle and suggests ways for further development and research.
\end{abstract}

\section{Keywords}

Publicness Level, VIKOR Model, Effectiveness, Truly Public or Not, Satisfaction Level, Qualities of Public Spaces

\section{Introduction}

"Urban public spaces are the places where everyday life of people, routine, ordinary or irregular and unusual activities take place" (Akkar Ercan \& Memlük, 2015: pp. 195-221). Many urban design researchers have argued for managing 
and creating public spaces in urban environment. Increasing privatization is the main reason behind declining publicness of public space. Due to rapid-urbanization, "commercialization, changing economic structures led to privatization, commodification, changing requirements of the people" etc. are affected to decline publicness (ER, 2019: p. 28). Declining inclusiveness is a prominent reason for declining publicness (Memlük, 2012). Therefore, many researchers debate on its importance related to how public spaces manage to more public. Therefore, re-considering about both managing and designing aspects is essential. Mainly different types of dimensions are used for evaluating publicness in urban public spaces. Based on previous studies, evaluating the publicness is a useful method to identify how much public is a space and it will help to find weaknesses and strengths of public space design in order to find solutions, which can increase accessibility and inclusion of a public space.

Sri Lankan cities have expanded rapidly since 1990s due to urbanization. Urban areas are faced with issues like densifying city core areas, stress, compactness, high-traffic-congestion, etc. Therefore, urban public spaces come into Sri Lankan context which promotes recreational activities, removes stressfulness, and emerges as the most important element in urban fabric. But Sri Lankan Government forgot the needs of people when creating public spaces as they cater to an international audience in Sri Lanka. Therefore, question arises like whether these existing public spaces are truly public or not? Most of the researchers are regarding the determinants of urban public spaces, those impacts for users' wellbeing, social interaction, etc. But there is no consideration regarding evaluating the publicness in urban public spaces in Sri Lanka when considering physical dimensions. Therefore, it can raise questions like available public spaces to have high publicness value or not? However, evaluating public space characters for publicness and providing recommendations to improve those are essential to provide guidance for urban planners, designers to develop these spaces with appropriate aspects during the rapid urbanization. Therefore, this research paper will achieve that knowledge gap and provide better functioning public spaces for local people in Galle. Under that, this study is based on three questions which are; what are the physical dimensions for evaluating the level of publicness of urban public spaces? And what indicators should be improved to increase the utilization/effectiveness of urban public spaces among users? And how far these public spaces are truly public or not? After solving these three questions, this study achieves four objectives which are; to evaluate the level of publicness of urban public spaces based on physical dimensions that are owned by public administration in Sri Lanka, to identify what parameters, need to evaluate the level of publicness and understand satisfaction levels of urban public spaces and key indicators, to assess how contributing indicators, influence to achieve the effectiveness of public spaces among users and to provide recommendations based on the experts' and users' views for future improvements of urban public spaces to enhance the publicness level in Sri Lanka. 


\section{Literature Review and Theories}

\subsection{Public Space \& Publicness}

The grouping of two words "public" and "space" defines a social space, which is normally open to and accessible for all age groups regardless of monetary or social differences. "Madanipour argued that public spaces should have two broad features that are accessibility and inclusion. In addition, Parkinson defined public space is freely accessible and democratic space with a provision of opportunities for strangers to meet and interact with each other" (Pourjafar, Zangir, Moghadam, \& Farhani, 2018).

\subsection{Dimensions of Publicness}

The government gives responsibility to create public spaces for private sector, it can miss the publicness level (Langstraat \& Melik, 2013). It can raise questions about what publicness exactly indicates. Therefore, scholars presented many interpretations of public spaces. But most researchers analyzed public space by using a descriptive/subjective perspective. There is rarely use a pragmatic approach, needed by many types of experts (planners with decision-making) to understand why certain public places fail and others succeed (Georgiana \& Damiano, 2013). Some scholars used models for evaluating publicness, those have limitations. Therefore, a democratic way is needed to evaluate publicness by using different dimensions.

When considering the dimensions of publicness, "Khon suggested, ownership, accessibility, and inter-subjectivity are core-dimensions. Young mentioned accessibility, inclusion, and tolerance as core-dimensions. Varna and Tiesdell (2010) described five dimensions as ownership, control, civility, physical configuration, and animation" (Kelleci, 2012). Above-mentioned dimensions based on "multifaceted-interpretation of what publicness includes. Therefore, Florian \& Rianne argued above-mentioned dimensions and they found four dimensions; ownership, management, accessibility, and inclusiveness. These dimensions are more effective than reducing publicness to a single concept" (Langstraat \& Melik, 2013). Fuzzy Inference System used management, access, and user as core-dimensions (Ekdi \& Çırac1, 2015). Pourjafar with team used a democratic way to evaluate publicness in public spaces. It calls a VIKOR model categorized as multi-criteria decision-making method. It used management, access, and user as dimensions (Pourjafar, Zangir, Moghadam, \& Farhani, 2018). Volkan described six morphological dimensions for publicness such as accessibility, permeability, continuity, imageability, complexity, and enclosure.

\subsection{Measuring the Publicness}

The level of publicness can change because of control elements applied in many public spaces. Those elements make that place more public or more private. Therefore, publicness measurement is important to evaluate level of publicness.

As indicated in Figure 1, the ownership dimension has a diverse effect on 
evaluating publicness (Pourjafar, Zangir, Moghadam, \& Farhani, 2018). Management is second dimension and it includes civility, control, and animation criteria which contain number of indicators. "Civility is maintaining and caring for public spaces in which increase attractiveness and welcoming of urban public spaces. Civility includes providing facilities such as physical maintenance, urban-furniture, provision of green space, public toilets, and lightning. Control has a direct relation to urban policies and basic human rights. It has two ways, which includes managing and designing public space. Managing public space contains zero-tolerance policy, using CCTV-cameras, Police force, and security-guards. Animation is in service of basic human needs and its utility is an important part of humans' social life. It identified human needs as comfort, relaxation, passive-engagement, active-engagement, etc. Therefore, providing sitting opportunities, infrastructure, and facilities for cycling and jogging, food vendors, opportunities for active-engagement and frontage are indicators for evaluating animation" (Pourjafar, Zangir, Moghadam, \& Farhani, 2018: p. 3).

Access is third dimension and it includes 3 criteria visibility, public transport, and pedestrian accessibility. Visibility is the most important factor to access public spaces from the streets and urban routes. "Designing specify and multiple entrances for a public place make citizens-especially those who are not familiar with area be able to easily access the space" (Pourjafar, Zangir, Moghadam, \& Farhani, 2018: p. 4). It can attract more people. Public transportation is the way of easy access to public spaces according to people's financial capabilities. Therefore, providing appropriate public transportation options can attract more people. The dimension of user is trying to measure perception of safety and varieties of activities in spaces. When providing high-security, people should feel safer and secure. Therefore, more users can attract a variety of leisure activities within that space (Pourjafar, Zangir, Moghadam, \& Farhani, 2018).

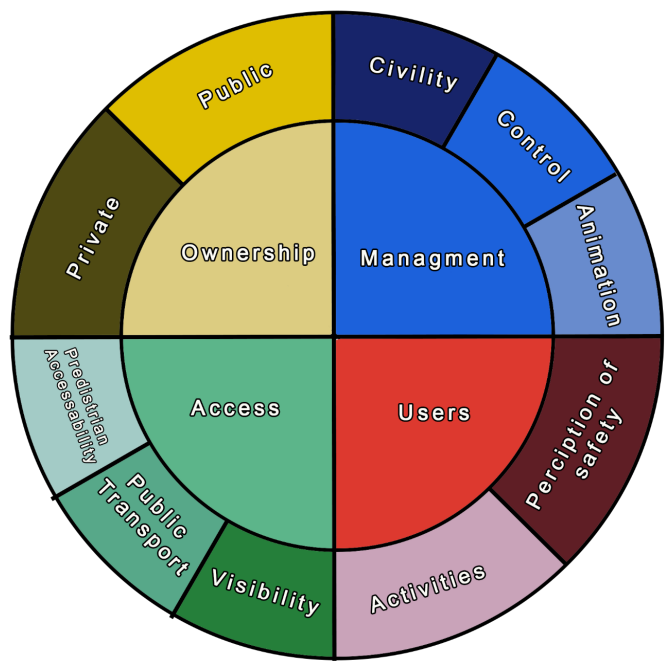

Figure 1. The frequented dimensions and criteria used in the existing literature. Source: (Pourjafar, Zangir, Moghadam, \& Farhani, 2018). 
According to that, Ownership, Management, Access, and User are the main dimensions for evaluating the publicness. This research focuses to evaluate these dimensions by using the VIKOR model.

\section{Research methodology}

Firstly, identify suitable model to evaluate the publicness level. When comparing the previous models, they only based on researcher's own observations and views. Those models are no much consideration into role of people, expert judgments. In practically, weighted indicators of dimensions have not gotten equal importance (Pourjafar, Zangir, Moghadam, \& Farhani, 2018). According to that, finally identify VIKOR model is suitable for evaluating the publicness level. In order to apply the VIKOR model in practice, and as it is expected to evaluate the publicness level in publicly owned and managed public spaces. Therefore, VIKOR model is a democratic way to evaluate level of publicness. Expert judgment can calculate weighted-values that are much closer to reality. Considering previous models' weaknesses, this model tries to evaluate the publicness based on users' and experts' judgments. This model is more reliable because it is a mathematical, multi-criteria decision-making model and its uses for many studies with different subjects (Büyüközkan \& Görener, 2015), (Huang, Tzeng, \& Liu, 2009). It is more suitable for ranking cases. It includes same dimensions, criteria, and indicators which have been used in previous models. It is a kind of summary of previous models. Therefore, the VIKOR model/multi-criteria decision-making tool is the most suitable model for evaluating publicness level of urban public spaces in Sri Lanka (Figure 2 \& Figure 3). This study focuses to evaluate publicness by using management, access, and user dimensions considering ownership classification by using a matrix. Figure 4 shows the steps of the VIKOR model used in this research.

Also, this study focuses on four locations in Galle. The case studies were selected based on on-site observations and secondary sources (using public space quality index criteria). The selected four case-studies are; Galle Fort (Sea Bath), Forest Park, Mahamodara Marine-walk, and Ocean Pathway in Galle MC. Figure 5 shows those locations.

\subsection{Methodological Framework}

The organizational framework has been conveyed by combination of all stages. This study mainly examines the publicness of public spaces in urban environment and to study those spaces are truly public or not? The following steps outline the methodology to achieve that, 1) identify the research gap in Sri Lanka and what are the dimensions to evaluate publicness; 2) comprehensive literature reviews for secondary data on the theories/concepts of public space and publicness and to identify the suitable models; 3 ) selection of Case studies for primary data and sample size, 4) data collection methods including a) on-site observations; b) questionnaire survey: data collection on the dimensions of management, access and users; c) semi-structured interviews: experts' ideas incorporate 


\begin{tabular}{|c|c|c|c|c|c|c|}
\hline \multirow[b]{2}{*}{ VIKOR Model - 2018} & \multicolumn{6}{|c|}{ Available of Dimensions, Crite ria \& Indicators in Previous Models } \\
\hline & $\begin{array}{l}\text { Cob Web } \\
\text { Model - } \\
2007\end{array}$ & \begin{tabular}{|c|} 
Linear \\
Method \& \\
Tri-Axal \\
Model - \\
2007 \& \\
2011 \\
\end{tabular} & $\begin{array}{l}\text { The Star } \\
\text { Model - } \\
2010\end{array}$ & $\begin{array}{c}\text { OMAI } \\
\text { Model - } \\
2013\end{array}$ & \begin{tabular}{|c} 
Fuzzy \\
Inference \\
System - \\
2015
\end{tabular} & $\begin{array}{c}\text { Polygon } \\
\text { Model } \\
\text { (still not } \\
\text { published) } \\
-2019\end{array}$ \\
\hline \multicolumn{7}{|l|}{ Dimensions } \\
\hline A. Management & & * & * & * & $*$ & * \\
\hline B. Access & * & * & * & * & * & * \\
\hline C. Users & * & * & * & * & * & * \\
\hline \multicolumn{7}{|l|}{\begin{tabular}{|r} 
Criteria \\
\end{tabular}} \\
\hline A1: Civility & & & $*$ & & $*$ & * \\
\hline A2: Control & * & * & * & * & * & * \\
\hline A3: Animation & * & & * & & * & * \\
\hline B1: Visibility & & * & * & * & * & * \\
\hline B2: Public transport & & & * & * & * & * \\
\hline B3: Pedestrian accessibility & * & * & * & * & * & * \\
\hline C1: Perception of Safety & & * & * & & * & \\
\hline C2: Activities & $*$ & * & $*$ & $*$ & $*$ & $*$ \\
\hline \multicolumn{7}{|l|}{ Indicators } \\
\hline $\begin{array}{l}\text { A11: Physical maintenance and } \\
\text { cleaning hard landscape area } \\
\text { and urban furniture }\end{array}$ & * & * & * & * & $*$ & * \\
\hline $\begin{array}{l}\text { A12: Physical maintenance and } \\
\text { provision of green space }\end{array}$ & * & & * & * & & * \\
\hline $\begin{array}{l}\text { A13: Physical maintenance and } \\
\text { provision of public toilets }\end{array}$ & & & & * & * & \\
\hline A14: Provision of lightening & & * & & * & * & \\
\hline A21: CCTV cameras & * & * & * & * & * & \\
\hline A22: Police/private guards & * & & * & * & * & \\
\hline A23: Sadistic street furniture & & & * & & & * \\
\hline A24: Control signage & & * & & $*$ & & * \\
\hline A31: Sitting opportunities & $*$ & * & $*$ & * & $*$ & * \\
\hline $\begin{array}{l}\text { A32: Infrastructure and } \\
\text { facilities for cycling and jogging }\end{array}$ & * & & & $*$ & * & * \\
\hline A33: Food/street vendors & * & * & & * & & * \\
\hline $\begin{array}{l}\text { A34: Active engagement and } \\
\text { Discovery }\end{array}$ & & & * & * & * & * \\
\hline A35: Active frontage & * & * & $*$ & & & $*$ \\
\hline B11: Visibility of site & & * & * & * & $*$ & \\
\hline $\begin{array}{l}\text { B21: Access to Bus Stops, } \\
\text { Metro Stations etc. }\end{array}$ & & & $*$ & * & * & * \\
\hline $\begin{array}{l}\text { B31: Pedestrian Walkways and } \\
\text { Cycling routes }\end{array}$ & & & * & * & * & * \\
\hline C11: Feeling Safe and Secure & & * & * & $*$ & $*$ & \\
\hline C21: Variety of Activities & * & $*$ & $*$ & $*$ & $*$ & $*$ \\
\hline
\end{tabular}

Figure 2. Suitability of VIKOR model for evaluating the publicness level.

\begin{tabular}{|c|c|c|}
\hline Dimensions & Criteria & Indicators \\
\hline \multirow{13}{*}{ A. Management } & \multirow{4}{*}{ A1: Civility } & $\begin{array}{l}\text { A11: Physical maintenance and cleaning hard landscape } \\
\text { area and urban furniture }\end{array}$ \\
\hline & & A12: Physical maintenance and provision of green space \\
\hline & & $\begin{array}{l}\text { A13: Physical maintenance and provision of public } \\
\text { toilets }\end{array}$ \\
\hline & & A14: Provision of lightening \\
\hline & \multirow{4}{*}{ A2: Control } & A21: CCTV cameras \\
\hline & & A22: Police/private guards \\
\hline & & A23: Sadistic street furniture \\
\hline & & A24: Control signage \\
\hline & \multirow{5}{*}{ A3: Animation } & A31: Sitting opportunities \\
\hline & & A32: Infrastructure and facilities for cycling and jogging \\
\hline & & A33: Food/street vendors \\
\hline & & A34: Active engagement and Discovery \\
\hline & & A35: Active frontage \\
\hline \multirow{3}{*}{ B. Access } & B1: Visibility & B11: Visibility of site \\
\hline & B2: Public transport & B21: Access to Bus Stops, Metro Stations etc. \\
\hline & B3: Pedestrian accessibility & B31: Pedestrian Walkways and Cycling routes \\
\hline \multirow{2}{*}{ C. Users } & C1: Perception of Safety & C11: Feeling Safe and Secure \\
\hline & C2: Activities & C21: Variety of Activities \\
\hline
\end{tabular}

Figure 3. VIKOR model dimensions, criteria and indicators. Source: (Pourjafar, Zangir, Moghadam, \& Farhani, 2018). 
Equation (1)

$$
Z_{i j}=\frac{Z^{1}+Z^{2}+Z^{3}+\cdots+Z^{p}}{p}
$$$$
\text { where } Z_{i j}=\left[\begin{array}{cccc}
Z_{11} & Z_{12} & \cdots & Z_{1 j} \\
Z_{21} & Z_{22} & \cdots & Z_{2 j} \\
\vdots & \vdots & \vdots & \vdots \\
Z_{i 1} & Z_{i 2} & \cdots & Z_{i j}
\end{array}\right]
$$

Equation (2)
Step 1 - Calculating the average of all experts' judgments. Each expert assesment forms an initial matrix $Z^{p}$ that is $\mathrm{n} \times \mathrm{n}$ matrix obtained by pair-wise comparisons in terms of importance between indicators by using five-scale ranging represented as no importance (1), very low importance (3), low importance (5), High Importance (7) and very high importance (9). For $\mathrm{p}$ experts the average $Z_{i j}$ of all experts' evaluations can be cal culated by using Equation (1).
$H_{i j}=\left[\begin{array}{cccc}H_{11} & H_{12} & \cdots & H_{1 j} \\ H_{21} & H_{22} & \cdots & H_{2 j} \\ \vdots & \vdots & \vdots & \vdots \\ H_{i 1} & H_{i 2} & \cdots & H_{i j}\end{array}\right]=\left[\begin{array}{cccc}Z_{11} / r_{1} & Z_{12} / r_{2} & \cdots & Z_{1 j} / r_{j} \\ Z_{21} / r_{1} & Z_{22} / r_{2} & \cdots & Z_{2 j} / r_{j} \\ \vdots & \vdots & \vdots & \vdots \\ Z_{i 1} / r_{1} & Z_{i 2} / r_{2} & \cdots & Z_{i j} / r_{j}\end{array}\right] \longrightarrow$ where $r_{j}=\sum_{i=1}^{n} Z_{i j}$

Equation (3)

$$
W_{i}=\left[\begin{array}{c}
W_{1} \\
W_{2} \\
\vdots \\
W_{i}
\end{array}\right]=\frac{1}{m}\left[\begin{array}{c}
H_{11}+H_{12}+\cdots+H_{1 j} \\
H_{21}+H_{22}+\cdots+H_{2 j} \\
\vdots \\
H_{i 1}+H_{i 2}+\cdots+H_{i j}
\end{array}\right]
$$

Equation (4)

$$
p_{i j}=\frac{p^{1}+p^{2}+p^{3}+\cdots+p^{k}}{k} \longrightarrow
$$

Equation (5)

$$
\begin{aligned}
& i=1,2, \cdots, n ; p_{j}^{+}=\max \left(p_{i j}, j=1, \cdots, J\right) \text { and } \\
& p_{j}^{-}=\min \left(p_{i j}, j=1, \cdots, J\right)
\end{aligned}
$$

Equation (6)

Equation (7)

$$
\begin{gathered}
S_{i}=\sum_{j=1}^{J}\left(W_{i} \times\left(\frac{\left(p_{j}^{+}-p_{i j}\right)}{p_{j}^{+}-p_{j}^{-}}\right)\right) \\
R_{i}=\max _{j}\left(W_{i} \times\left(\frac{\left(p_{j}^{+}-p_{i j}\right)}{p_{j}^{+}-p_{j}^{-}}\right)\right)
\end{gathered}
$$

Equation (8)

$$
\begin{gathered}
R_{i}^{+}=\max \left(R_{i}, i=1,2,3, \cdots, I\right) \quad= \\
R_{i}^{-}=\min \left(R_{i}, i=1,2,3, \cdots, I\right) \\
\text { Equation (10) } \\
Q_{i}=v \times\left(\frac{\left(S_{i}-S_{i}^{-}\right)}{\left(S_{i}^{+}-S_{i}^{-}\right)}\right)+(1-v) \times\left(\frac{\left(R_{i}-R_{i}^{-}\right)}{\left(R_{i}^{+}-R_{i}^{-}\right)}\right)
\end{gathered}
$$$$
S_{i}^{+}=\max \left(S_{i}, i=1,2,3, \cdots, I\right)
$$$$
S_{i}^{-}=\min \left(S_{i}, i=1,2,3, \cdots, I\right)
$$

Equation (9)

Equation (11)

$$
Q^{\prime}=\frac{Q_{\text {worst scenario }}-Q_{i}}{Q_{\text {worst scenario }}} \times 10,(i=1,2,3, \cdots, n)
$$

Step 2 - Normalizing the average of all experts' judgment. For acquiring normalized matrix $\left(H_{j}\right)$, each element of matrix $Z_{i j}$ divided by the sum of its column $(\mathrm{N})$. Therefore, sum of each column equals 1 .

Step 3 - Obtaining weights of each indicator Weights for each indicator can be acquired by calculating Eigen vector. Eigen vector can obtain by averaging across the rows of matrix $\mathrm{Hj}$ through using Equation (3). In Equation (3) $m$ value is the number of indicators and matrix $W_{i}$ has one-column and $m$ rows.

Step 4- Calculating the average of all users' scores. Score of each indicator will be the average of all users' assessments. For obtaining the average of $k$ users scores, Equation (4) is used as same as Equation (1). Matrix $p_{i j}$ is calculated based on dividing sum of $p^{k}$ with the number of users.

Step 5 - Define the more public $p_{j}^{+}$and the more private $p_{j}^{-}$values of all indicators function. The top and the bottom of scores can, be calculated by using follow equation.

Step 6 - Compute the values $S_{i}$ and $R_{i}$. These two parameters also known as weighted and normalized Manhattan distance $\left(S_{i}\right)$ and weighted and normalized Chebyshev distance $\left(R_{i}\right)$ which are calculated by using Equation (6)-Equation (7):

Step 7 - Finding the final value $\left(Q_{i}\right)$. Before calculating the last value for each case study, computing four parameters are necessary to obtain $Q_{i}$ value. These parameters include $S_{i}^{+}, S_{i}$ $R_{i}^{+}$and $R_{i}^{-}$, which computes by using follow equations.

After that, the final value of $Q_{i}$ can be computed by the equation number 10

Step 8 - Rank the case studies. The result should be sorted by the Values of $S, R$ and $Q$ for each case study and from the minimum value.

The lowest value of $Q$ represents a public place dlose to more public and the biggest one shows the coseness to more private. Furthermore, for better interpreting ranking system based on $Q$ value of each case study Equation (11) employed to calculating the level of publicness $\left(Q^{\prime}\right)$ in scale of 0 to 10 , which zero represents fully private and 10 shows fully public.

Figure 4. Eight steps of VIKOR model. Source: (Pourjafar, Zangir, Moghadam, \& Fathani, 2018). 


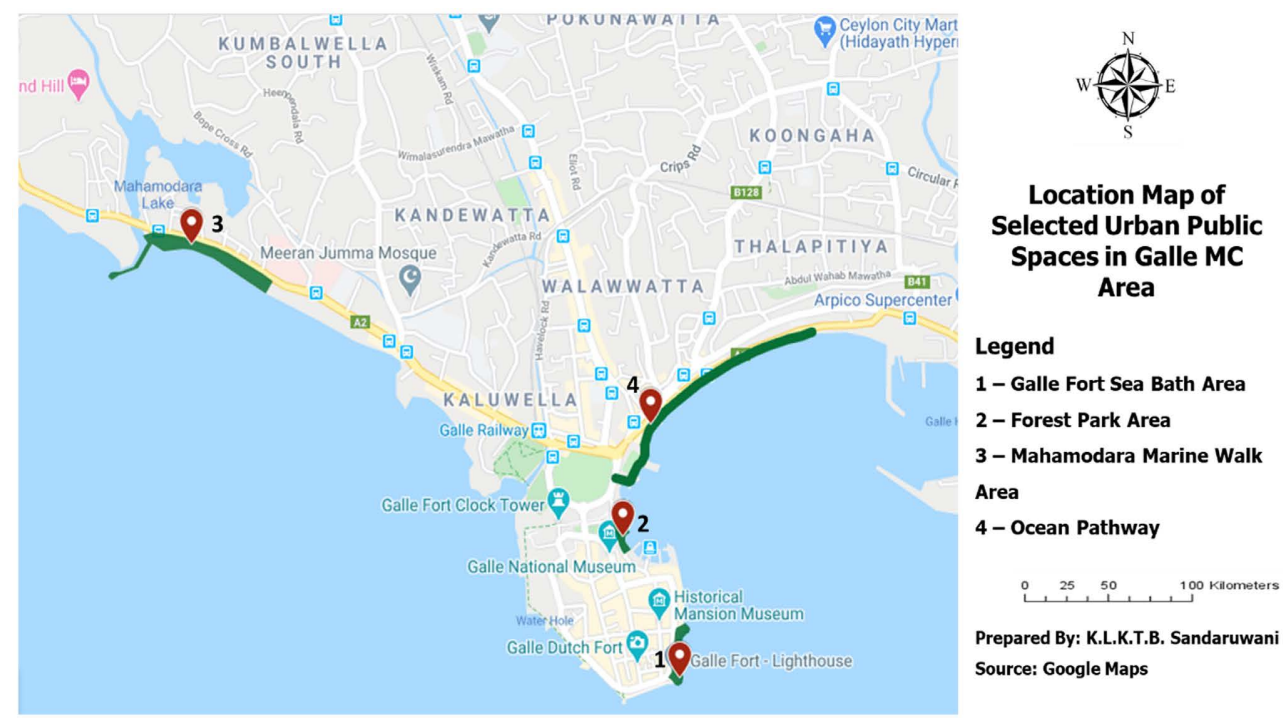

Figure 5. Location map of selected case studies in Galle. Source: compiled by author.

to meet objectives to provide recommendations-based experts' and users' views for the future design of public spaces. To calculate weights of each indicator, nine experts involve of three civil engineers, three planning officers, and three town planners are interviewed, including definition of dimensions of the publicness (including criteria and indicators), and case studies were explained to them, and at the end they were asked to fill a questionnaire which shows importance between indicators; d) photographic documentation; and 5) data analysis methods including both quantitative and qualitative methods: a) analysis data through VIKOR modelling; b) analytic hierarchy process (AHP) analysis; c) descriptive statistics; and d) content analysis and photographing. Stage 3 and 4 concentrates on data gathering and data evaluation with the mixed-method. All the charts, tables, diagrams of models will be prepared by using the SPSS and MS Excel-2019 software.

\section{Selection of Sample Size}

The sampling method used in the study can be interpreted as the non-probability sampling method. It selects mainly because the study is based on users of particular selected public spaces. The related studies use this sampling method, which is selected based on nature of research process. Within non-probability sampling, the convenience-sampling selects to carry-out an oral-interview questionnaire survey, and purposive sampling uses in the qualitative study which is a semistructured interview. The sample size is determined as user-count through observation which is a total of peak-hour observation in a day. An average value is taken based on the observation and $10 \%$ of users selected from each public space due to time limitations and Covid-19 pandemic situation. The sample includes the age level $\geq 15$ because low-level of age category will make disruption in data collecting time. So, the collected information may not have reliability/validity. Accordingly, it can obtain approximately 200 questionnaires. 9 experts include semi-structured interviews. 


\section{Analysis \& Findings}

\subsection{Q1 - What Are the Physical Dimensions for Evaluating the Level of Publicness of Urban Public Spaces?}

\subsubsection{Stage 1-Assess the Importance of Contributing Indicators to Evaluate the Publicness Level of Public Spaces}

After choose model, assesses the importance of contributing indicators. The contributing indicators identified through literature review. These indicators assess in four case-studies to study publicness level. Experts' judgments are taken into concern for calculating the importance of contributing indicators in planning/designing, and construction of public spaces. According to that, all weights of each indicator identify through nine expert judgments. Through Equations (1)-(3), indicators' weights are calculated (Figure 6). The highest importance has "sadistic street furniture, visibility of the site, and feeling safe and secure" indicators as scored 0.09. The second importance has "public transport like bus stops, metro station" etc. as scored 0.08. "Control signage" has the least importance compared to others and it scored 0.02. Figure 7 shows visual representation of that. According to that, "management and control" have the highest weights among all dimensions and indicators.

Satisfaction level of contributing indicators for evaluating publicness level

When considering the satisfaction level of each indicator, most experts agree with these physical dimensions for evaluating the publicness level. Sitting opportunities, quality of pedestrian walkways, cycling routes, and feel safe and secure indicators have high satisfaction-level above $85 \%$ among experts' views (Figure 8). The satisfaction level always links with publicness level. Because the contributing factors satisfaction mainly leads to decide the publicness level. When considering the user perception (Figure 9) most user are satisfied model indicators. Some of them are not satisfied in CCTV indicator because they thought it is the disturbing element of their freedom.

\begin{tabular}{|c|c|c|c|c|c|c|c|c|c|c|c|c|c|c|c|c|c|c|c|c|c|}
\hline \multirow{4}{*}{\begin{tabular}{|c|}
$\begin{array}{c}\text { Dime } \\
\text { nsion }\end{array}$ \\
$\begin{array}{c}\text { Criteri } \\
\text { a }\end{array}$ \\
$\begin{array}{c}\text { Indicat } \\
\text { or }\end{array}$ \\
\end{tabular}} & & & & & & & & & & & & & & & & & & & \multicolumn{3}{|c|}{ Number of indicators $=18$} \\
\hline & \multicolumn{13}{|c|}{ Management A. } & \multicolumn{3}{|c|}{ Access B. } & \multicolumn{2}{|c|}{ Users C. } & \multirow{3}{*}{ Sum } & \multirow{3}{*}{$\begin{array}{c}\text { Weigh } \\
\text { ts }\end{array}$} & \multirow{3}{*}{$\begin{array}{c}\text { Rank } \\
\text { of } \\
\text { Indica } \\
\text { tors }\end{array}$} \\
\hline & \multicolumn{4}{|c|}{ A1. } & \multicolumn{4}{|c|}{ A2. } & \multicolumn{5}{|c|}{ A3. } & B1. & B2. & B3. & C1. & C2. & & & \\
\hline & A11. & A12. & A13. & A14. & A21. & A22. & A23. & A24. & A31. & A32. & A33. & A34. & A35. & B11. & B21. & B31. & C11. & C21. & & & \\
\hline A11 & 0.02 & 0.02 & 0.04 & 0.02 & 0.05 & 0.04 & 0.01 & 0.02 & 0.03 & 0.03 & 0.05 & 0.04 & 0.03 & 0.05 & 0.04 & 0.01 & 0.06 & 0.04 & 0.60 & 0.03 & 7 \\
\hline A12 & 0.05 & 0.02 & 0.06 & 0.07 & 0.04 & 0.03 & 0.07 & 0.06 & 0.04 & 0.04 & 0.06 & 0.05 & 0.02 & 0.07 & 0.09 & 0.05 & 0.07 & 0.02 & 0.89 & 0.05 & 5 \\
\hline A13 & 0.03 & 0.02 & 0.01 & 0.03 & 0.07 & 0.06 & 0.09 & 0.04 & 0.04 & 0.04 & 0.06 & 0.05 & 0.04 & 0.02 & 0.12 & 0.03 & 0.04 & 0.02 & 0.80 & 0.04 & 6 \\
\hline A14 & 0.07 & 0.03 & 0.03 & 0.02 & 0.06 & 0.05 & 0.08 & 0.05 & 0.07 & 0.03 & 0.07 & 0.07 & 0.03 & 0.03 & 0.09 & 0.00 & 0.04 & 0.01 & 0.82 & 0.05 & 5 \\
\hline A21 & 0.06 & 0.07 & 0.07 & 0.07 & 0.03 & 0.05 & 0.05 & 0.07 & 0.13 & 0.07 & 0.10 & 0.08 & 0.07 & 0.06 & 0.05 & 0.10 & 0.07 & 0.12 & 1.30 & 0.07 & 3 \\
\hline A22 & 0.06 & 0.07 & 0.07 & 0.06 & 0.08 & 0.03 & 0.07 & 0.05 & 0.11 & 0.07 & 0.07 & 0.07 & 0.06 & 0.07 & 0.02 & 0.09 & 0.05 & 0.09 & 1.18 & 0.07 & 3 \\
\hline $\mathbf{A 2 3}$ & 0.09 & 0.08 & 0.09 & 0.08 & 0.12 & 0.10 & 0.05 & 0.09 & 0.05 & 0.10 & 0.06 & 0.08 & 0.08 & 0.12 & 0.07 & 0.09 & 0.05 & 0.10 & 1.53 & 0.09 & 1 \\
\hline A24 & 0.02 & 0.02 & 0.02 & 0.01 & 0.03 & \begin{tabular}{|l|}
0.03 \\
\end{tabular} & 0.01 & 0.01 & 0.01 & 0.00 & 0.01 & 0.00 & 0.01 & 0.01 & 0.07 & 0.04 & \begin{tabular}{|l|l|}
0.04 \\
\end{tabular} & 0.02 & 0.37 & 0.02 & 8 \\
\hline A31 & 0.05 & 0.04 & 0.04 & 0.04 & 0.01 & \begin{tabular}{|l|} 
\\
\end{tabular} & 0.08 & 0.08 & 0.03 & 0.04 & 0.07 & 0.08 & \begin{tabular}{|l|}
0.08 \\
\end{tabular} & 0.07 & 0.07 & 0.06 & \begin{tabular}{|l|l|}
0.08 \\
\end{tabular} & 0.06 & 1.02 & 0.06 & 4 \\
\hline A32 & 0.06 & 0.05 & 0.05 & 0.06 & 0.04 & 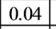 & 0.01 & 0.07 & 0.05 & 0.02 & 0.07 & 0.03 & 0.07 & 0.03 & 0.04 & 0.04 & \begin{tabular}{|l|} 
\\
\end{tabular} & 0.03 & 0.86 & 0.05 & 5 \\
\hline A33 & 0.02 & 0.03 & 0.02 & 0.01 & 0.00 & 0.03 & 0.05 & 0.05 & 0.05 & 0.02 & 0.01 & 0.00 & 0.01 & 0.01 & 0.01 & 0.02 & 0.07 & 0.06 & 0.48 & 0.03 & 7 \\
\hline A34 & 0.05 & 0.04 & 0.05 & 0.02 & 0.02 & \begin{tabular}{|l|l|} 
\\
\end{tabular} & 0.01 & 0.06 & 0.01 & 0.05 & 0.05 & 0.02 & \begin{tabular}{|l|}
0.04 \\
\end{tabular} & 0.01 & 0.02 & 0.01 & \begin{tabular}{|l|l|}
0.04 \\
\end{tabular} & 0.04 & 0.57 & 0.03 & 7 \\
\hline A35 & 0.05 & 0.06 & 0.06 & 0.06 & 0.03 & 0.06 & 0.01 & 0.04 & 0.01 & 0.02 & 0.04 & 0.03 & \begin{tabular}{|l|}
0.02 \\
\end{tabular} & 0.03 & 0.02 & 0.03 & \begin{tabular}{|l|}
0.01 \\
\end{tabular} & 0.01 & 0.58 & 0.03 & 7 \\
\hline B11 & 0.08 & 0.12 & 0.10 & 0.12 & 0.15 & 0.07 & 0.04 & 0.07 & 0.11 & 0.11 & 0.08 & 0.09 & \begin{tabular}{|l|}
0.08 \\
\end{tabular} & 0.04 & 0.06 & 0.09 & \begin{tabular}{|l|l|}
0.08 \\
\end{tabular} & 0.09 & 1.57 & 0.09 & 1 \\
\hline B21 & 0.07 & 0.06 & 0.05 & 0.08 & 0.09 & 0.16 & 0.11 & 0.06 & 0.08 & 0.09 & 0.08 & 0.10 & 0.10 & 0.13 & 0.03 & 0.12 & \begin{tabular}{|l|} 
\\
\end{tabular} & 0.08 & 1.53 & 0.08 & 2 \\
\hline B31 & 0.07 & 0.07 & 0.07 & 0.10 & 0.05 & 0.04 & 0.05 & 0.05 & 0.03 & 0.05 & 0.04 & 0.07 & 0.06 & 0.04 & 0.03 & 0.02 & \begin{tabular}{|l|} 
\\
\end{tabular} & 0.05 & 0.95 & 0.05 & 5 \\
\hline C11 & 0.08 & 0.09 & 0.08 & 0.07 & 0.08 & \begin{tabular}{|l|l|} 
\\
\end{tabular} & 0.13 & 0.06 & 0.07 & 0.12 & 0.06 & 0.09 & \begin{tabular}{|l|l|}
0.11 \\
\end{tabular} & 0.14 & 0.09 & 0.13 & \begin{tabular}{|l|l|}
0.04 \\
\end{tabular} & 0.11 & 1.66 & 0.09 & 1 \\
\hline C21 & 0.09 & 0.09 & 0.08 & 0.08 & 0.04 & \begin{tabular}{|l|} 
\\
\end{tabular} & 0.04 & 0.06 & 0.08 & 0.10 & 0.04 & 0.07 & \begin{tabular}{|l|}
0.09 \\
\end{tabular} & 0.09 & 0.08 & \begin{tabular}{|l|l|} 
\\
\end{tabular} & 0.12 & 0.03 & 1.27 & 0.07 & 3 \\
\hline
\end{tabular}

Figure 6. Weighted values of dimensions, criteria, and indicators through experts' judgments. Source: compiled by the author according to experts survey. 


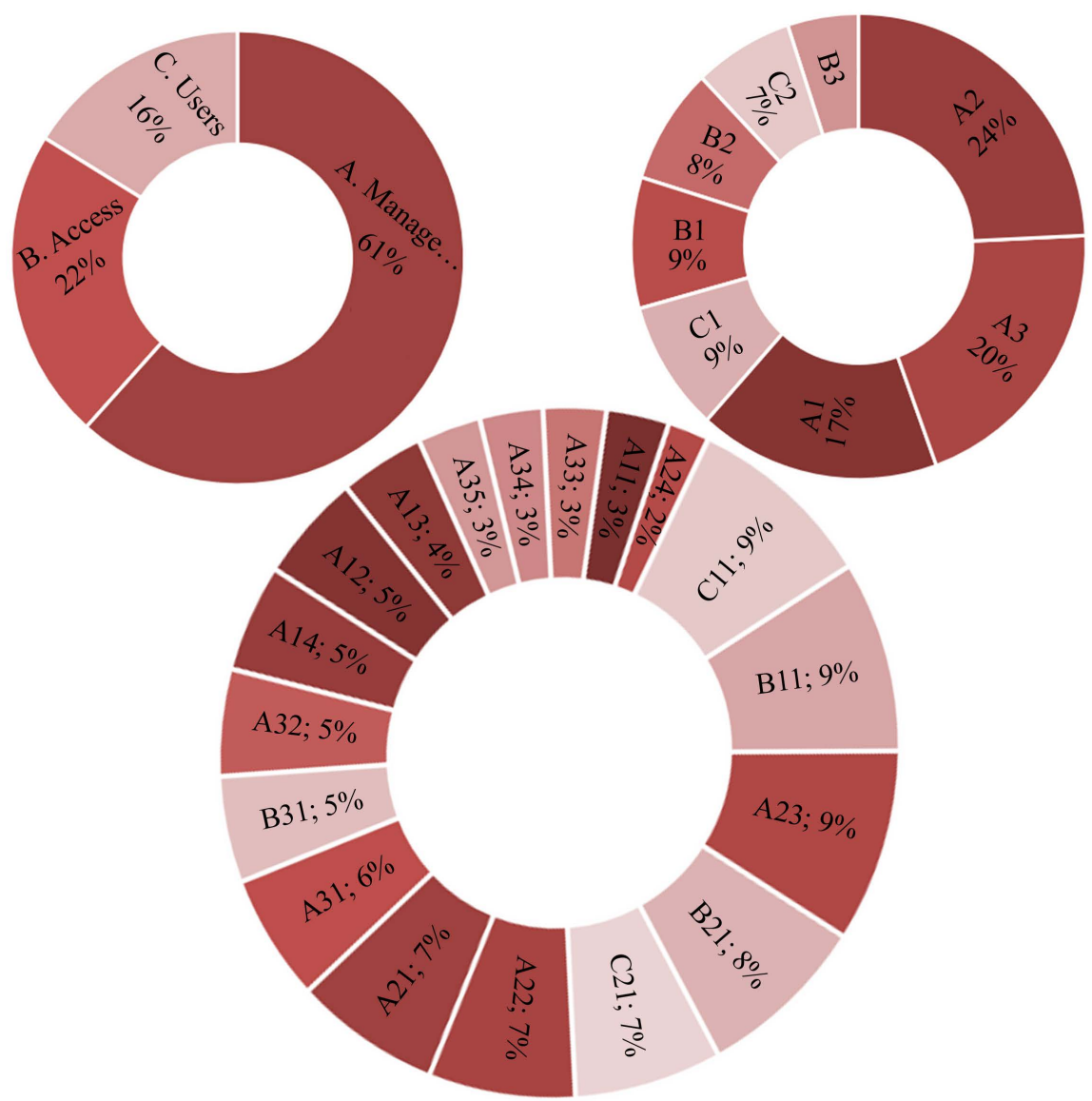

Figure 7. Visual representation of weights in percentage format. Source: compiled by author.

\begin{tabular}{|c|c|c|c|}
\hline \multirow{2}{*}{$\begin{array}{c}\text { Indicators } \\
\text { Question wise) }\end{array}$} & \multicolumn{3}{|c|}{ Satisfaction Level (Percentage format) } \\
\cline { 2 - 4 } & Very Satisfied (\%) & Neutral (\%) & Dissatisfied (\%) \\
\hline Q1 & 77.8 & 22.2 & N/A \\
\hline Q2 & 66.7 & 22.2 & 11.1 \\
\hline Q3 & 44.4 & 55.6 & N/A \\
\hline Q4 & 55.6 & 44.4 & N/A \\
\hline Q5 & 55.6 & 44.4 & 11.1 \\
\hline Q6 & 22.2 & 66.7 & N/A \\
\hline Q7 & 66.7 & 33.3 & N/A \\
\hline Q8 & 55.6 & 44.4 & N/A \\
\hline Q9 & $\mathbf{8 8 . 9}$ & 11.1 & 11.1 \\
\hline Q10 & 66.7 & 33.3 & N/A \\
\hline Q11 & 55.6 & 33.3 & N/A \\
\hline Q12 & 66.7 & 33.3 & N/A \\
\hline Q13 & 77.8 & 22.2 & 22.2 \\
\hline Q14 & 77.8 & 22.2 & N/A \\
\hline Q15 & 33.3 & 44.4 & N/A \\
\hline Q16 & $\mathbf{8 8 . 9}$ & 11.1 & N/A \\
\hline Q17 & $\mathbf{8 8 . 9}$ & 11.1 & \\
\hline Q18 & 77.8 & 22.2 & \\
\hline
\end{tabular}

Figure 8. Satisfaction level of contributing indicators according to experts. Source: compiled by author. 


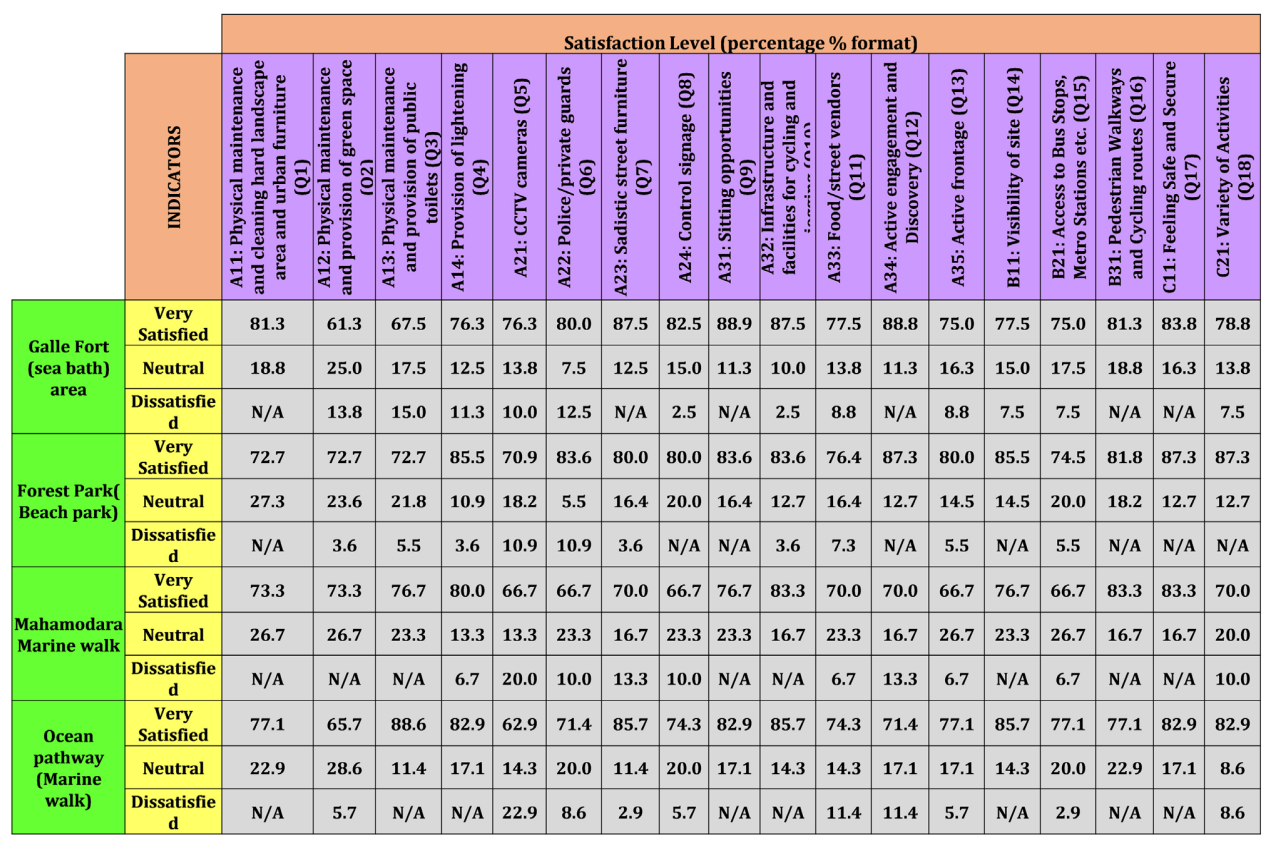

Figure 9. Satisfaction level of contributing indicators according to users. Source: compiled by author.

\subsubsection{Stage 2-Assess the Performance of Each Indicator According to Four Case Studies}

At this stage, mainly evaluate each indicator's performance according to each case-study. It gives an idea about publicness level in each case-study through questionnaire survey among users.

As illustrated in Figure 10, in Galle Fort (Sea Bath), 80 users are respondents to survey. According to that, the lowest score record to "physical maintenance and provision of public toilets" indicator as scored 1.91. "Active engagement and discovery" indicator obtain a high score as 7.15. Because Galle Fort is the one of world heritage and it has beautiful scenery and provides various types of activities for people.

55 respondents participated survey in Forest Park. The lowest score relates to "perception about CCTV cameras" indicator. Users' concern CCTV element is a disturbing element for their freedom. "Physical maintenance and provision of green space" indicator get high score of 9.64. According to observations, this space provides more benches under huge trees.

30 users are respondent survey in Mahamodara Marine-walk. Lots of 15 - 25 age group people are using this space according to observations. Most of them are couples. According to survey, "provision of lightening" indicator gets the lowest score as 1.37. Because this space is not maintaining and all lights are broken.

Users said that "At night time, we cannot use this space because it looks darker nature, therefore some illegal activities are happening. It scares us to come here at night". During experts' interview, one expert said that "some people are broken lights and they create this space as small spot for their illegal activities". 


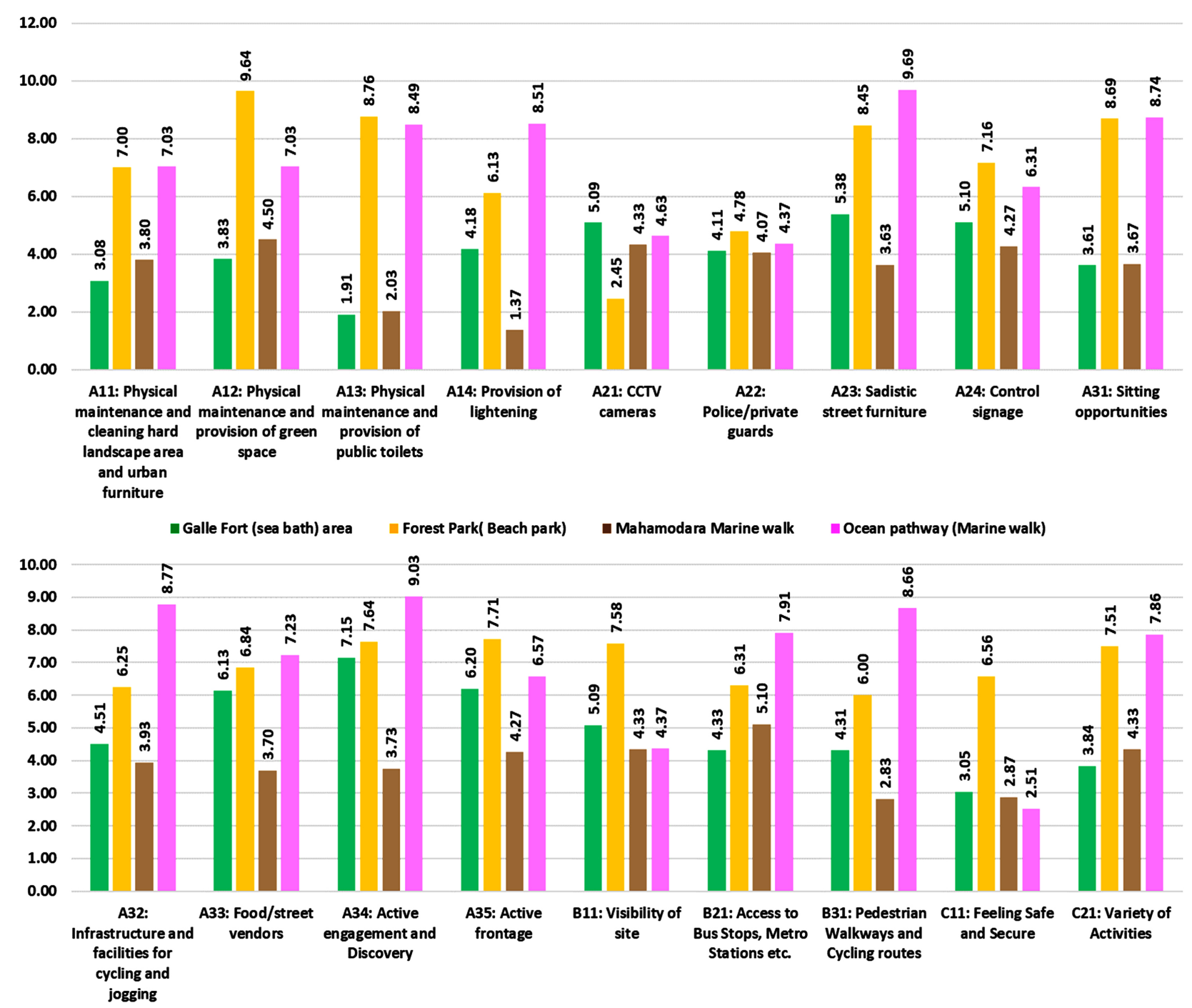

Figure 10. Average values of all users' judgments based on indicators in four case studies. Source: compiled by author.

The highest score relates to "access to bus stops, metro stations, etc." indicator because bus stops are locating near this space. Therefore, people can easily access this space.

The ocean pathway, 35 users are respondents to survey. "Feeling safe and secure" indicator gets the lowest score as 2.51 . Because there are unstable huts which are created by fishermen. Those houses take on an ugly nature to this space. "No sadistic street urban furniture" indicator gets the highest score as 9.69. Because this space is well maintaining. Also, people can easily access this space because it is located near Galle town. This space is more suitable for jogging, watching, sitting, eating, and taking photographs. Therefore, this space is more functioning in town area.

\subsubsection{Stage 3-Calculate the Level of Publicness in Four Case Studies}

This stage mainly focuses to calculate the publicness level based on VIKOR model in four case studies. It mainly considers the average values of all users' 
judgments of indicators (Figure 11). It decides publicness level in each case study. Because users are the people who are using these spaces as usual. Under the VIKOR model, the $\mathrm{Q}$ value should be arranged in descending order and decide on what case study has high-level and what case study has low-level publicness. Therefore, the Q' value concerns rank case studies. Equation (10) and (11) use for evaluating the publicness level. Furthermore, publicness level has scale of 0 to 10 values. 0 represents the worst publicness level (fully private) and 10 represents the best publicness level (fully public). Based on VIKOR model analysis, Forest Park has high publicness level as scored 5.04. Mahamodara Marine Walk has the lowest level of publicness as scored 2.63. According to ranking, 1) Forest Park, 2) Ocean Pathway, 3) Galle Fort, and 4) Mahamodara Marine-walk.

According to ownership classification, all case studies have public-ownership, public-function, and public-use (Figure 12).

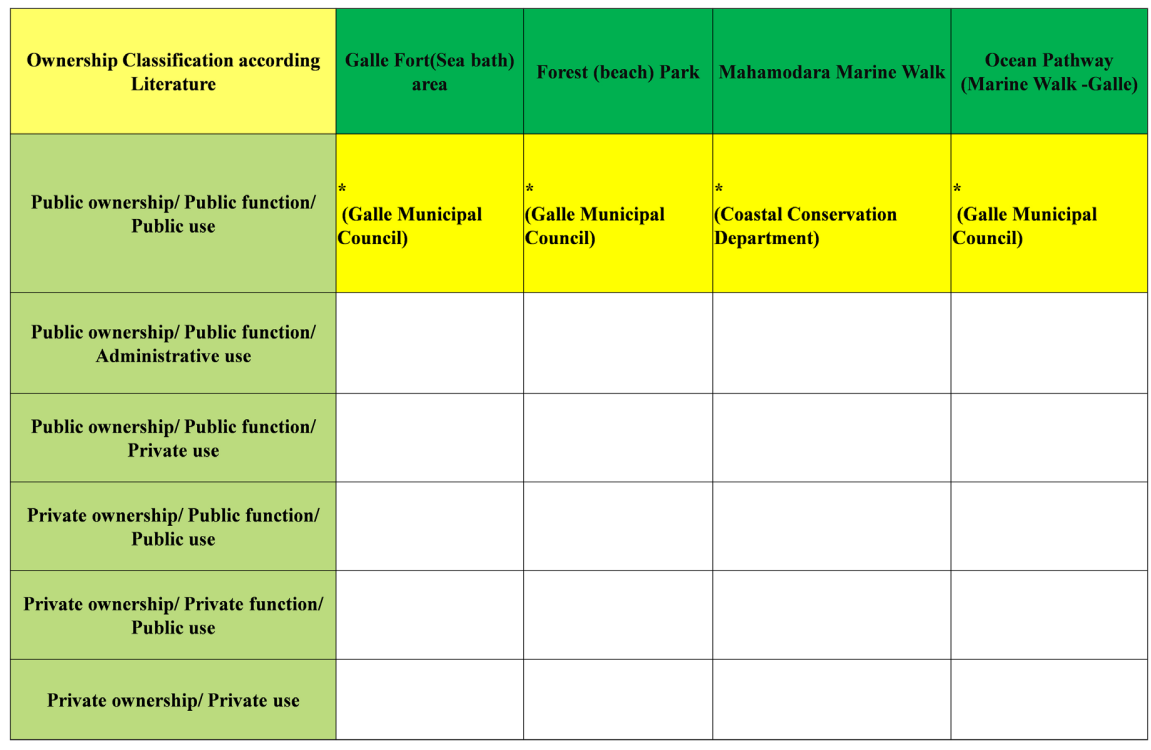

Figure 11. Ownership classification of case studies.

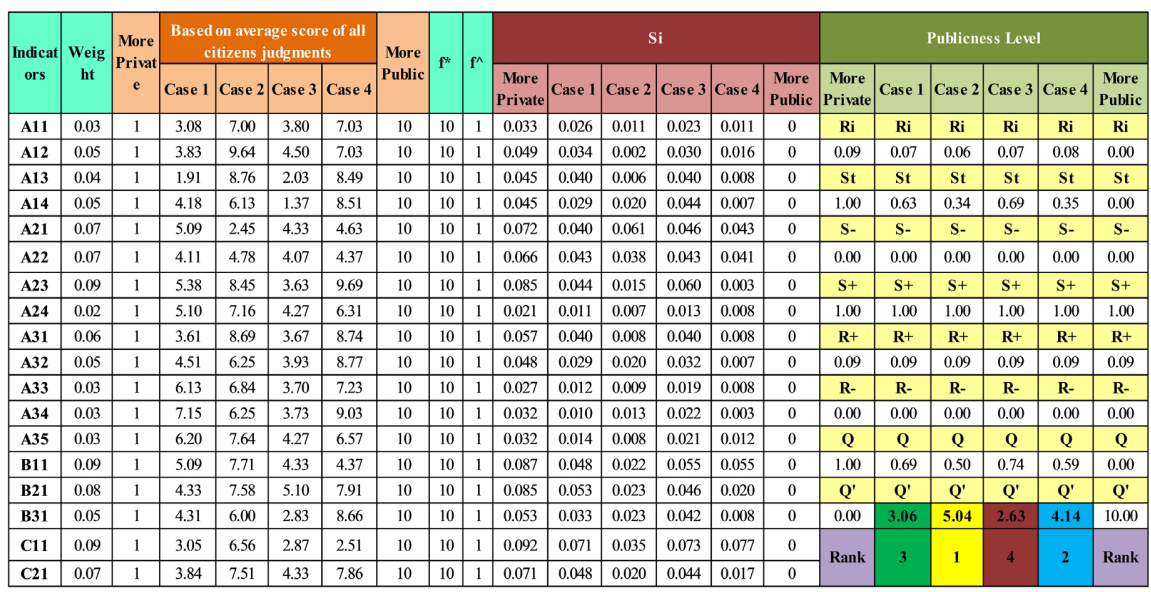

Figure 12. Evaluating the publicness level based on four case studies. Source: compiled by the author based on user judgment. 
When comparing overall satisfaction level and publicness level among four case studies, Forest Park has high score (Figure 13). Accordingly, people like to live and spend time in these spaces. The satisfaction level is shown in Figure 14.

\subsection{Q2 - What Indicators Should Be Improved to Increase the Utilization/Effectiveness of Urban Public Spaces among Users?}

Objectives 2 and 3 can achieve when solving research questions 2 and 3 .

\subsubsection{Indicators Improve the Effectiveness}

The experts' views generated through semi-structured interviews and oral-interview questionnaire surveys used to identify indicators should be improved to increase the utilization of public spaces. According to the experts' point of view, there are several indicators identified to improve/increase utilization. According to those views, a good operating system needs to control these spaces. Then, it can improve high publicness level of public spaces.

\subsubsection{Users' Perception towards Enhancing the Publicness Level and Effectiveness of Public Spaces}

This section elaborates on comments provided by users regarding enhancing the

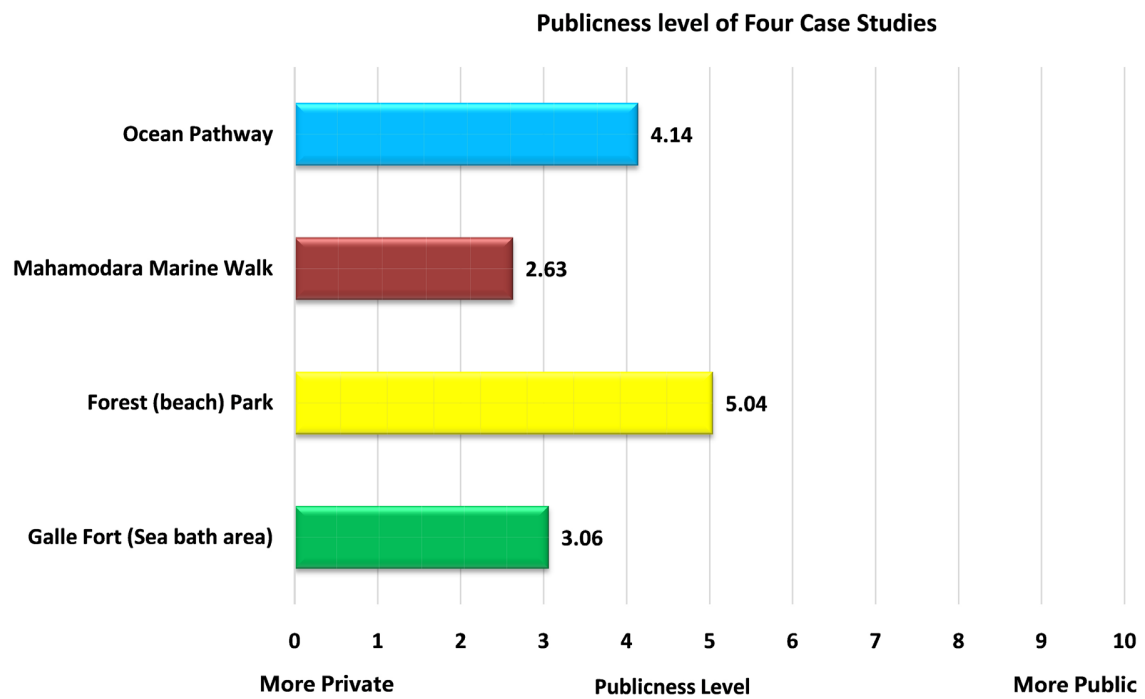

Figure 13. Publicness Level of four case studies. Source: compiled by author.

\begin{tabular}{|c|c|c|c|c|c|c|c|c|}
\hline \multirow{2}{*}{$\begin{array}{c}\text { Satis faction } \\
\text { Level }\end{array}$} & \multicolumn{2}{|c|}{$\begin{array}{c}\text { Galle Fort(Sea bath) } \\
\text { area }\end{array}$} & \multicolumn{2}{c|}{\begin{tabular}{c}
\multicolumn{2}{c|}{ Forest (beach) Park } \\
\cline { 2 - 9 }
\end{tabular}} & $\begin{array}{c}\text { Mahamodara Marine } \\
\text { Walk }\end{array}$ & $\begin{array}{c}\text { Ocean Pathway (Marine } \\
\text { Walk -Galle) }\end{array}$ \\
\hline Ferequency satisfied & 34.0 & 42.5 & 44.0 & 80.0 & N/A & N/A & 21.0 & 60.0 \\
\hline Satis fied & 28.0 & 35.0 & 6.0 & 10.9 & 5.0 & 16.7 & 9.0 & 25.7 \\
\hline Neutral & 8.0 & 10.0 & 5.0 & 9.1 & 8.0 & 26.7 & 4.0 & 11.4 \\
\hline Dissatisfied & 8.0 & 10.0 & N/A & N/A & 14.0 & 46.7 & 1.0 & 2.9 \\
\hline $\begin{array}{c}\text { Very } \\
\text { Diss atisfied }\end{array}$ & 2 & 3 & N/A & N/A & 3 & 10 & N/A & N/A \\
\hline
\end{tabular}

Figure 14. Overall Satisfaction level of four case studies. Source: Compiled by author. 
publicness level and improving utilization of public spaces. These two studies will be beneficial to upgrade the effective utilization of these public spaces' infrastructures and to increase publicness level in the future.

According to user perception, they provided several comments on improving utilization and increasing publicness level. Maintain and cleanliness inside the public spaces and furniture, awareness programs through visual interpretations to aware public about the importance of infrastructures usage, provide feel safe, secure and high accessible space for all, provide high-quality pedestrian walkways, cycling routes and sitting facilities for all age groups, provide lights for dark hours to increase effectiveness of space and control signages visible to all users and newcomers to city which is easily understandable and attractive way are some of the comments according to users' view.

\subsubsection{Experts' and Users' Views of Barriers \& Reason for Underutilization}

There are reasons for underutilization and barriers to development of public spaces which have been identified by users as well as through experts. Initially, the reasons for underutilization are explained, and elaborate on the barriers to development of public spaces.

Before the construction, eligibility assessment and feasibility studies are carried out. However, after the construction, no monitoring studies to show the progress of the particular construction. This is identified as main reason for underutilization. According to their views, it will be beneficial to identify problems that arise after the construction and upgrade their process in upcoming works. Other reasons for underutilization are no proper operationalize system, no maintenance, not provided accessibility for disabled people, not located in strategic location, no public awareness, no proper security system, presence of beggars, drug dealers, fear of being assaulted in spaces discourage the users not to use. The main barriers to the development of public spaces in Sri Lanka are identified by experts as cost and fund. However, cost is high and lack of funds is always paving a way to go for an option. It also leads to underutilization. Also, some regulations affect to stop some developments in these spaces.

\section{Conclusions and Discussions}

The findings are explored by addressing each research question of the study. Subsequently, the results which answer the question one identifies by comparing four cases, publicness level, and overall satisfaction-level are highly recorded in Forest Park. VIKOR model is the most suitable and efficient model for evaluating publicness level based on experts' and users' judgments. It is more applicable and visualizing model for Sri Lankan context. Publicness indicators assess based on users' judgments. Because citizens are daily users and it will get reliable answers for this study. Therefore, there are gaps between experts' and users' views. The comparison between contributing indicators for effectiveness indicated that physical infrastructures and maintenance as the most influencing indicators. The 
satisfaction level explored that the users are highly satisfied with the "physical maintenance and no sadistic urban furniture" while dissatisfied with the "CCTV camera" indicators. Experts are highly satisfied with the "sitting opportunities and feel safe/secure" indicators. However, many experts' views are the effective utilization of these spaces infrastructures depends on attitude and behavioral pattern of users. These findings prove the elements that are included in Urban Design Theory are important to those spaces. Also, this study talks about what indicators should be improved, what are reasons for underutilizing of public spaces, and users' perception of key indicators. Finally, it assesses those who are truly public or not. According to user judgment, Galle Fort, Forest Park, and Ocean Pathway are truly public. But Mahamodara Marine Walk is not public based on user views. Because it is not maintaining, no lighting and it feels unsafe and insecure space.

According to ownership classification, those are fully-public because those have public-ownership, public-function, and public-use. Only managing and control are two different things among case studies. Furthermore, this study is more reliable because experts' judgment decreases the self-errors and gets true answers than assessing users. To recap, this study tried to clear documentation for assessing by people and fulfill gaps of previous models, which made final result closer to reality. Finally, users' judgment is used VIKOR model for getting final results and illustrating that assessment. Therefore, this model is an efficient model to evaluate the publicness level, and urban planners/designers can analyze urban issues easily. The study findings are focused on evaluating publicness level that achieves social and physical sustainability of spaces which makes benefit for urban planners/designers \& decision-makers who are working in built-environment within the community as well spaces are created for community gathering purpose in Sri Lanka is proved under these result interpretations.

\section{Conflicts of Interest}

The authors declare no conflicts of interest regarding the publication of this paper.

\section{References}

Akkar Ercan, M., \& Memlük, N. (2015). More Inclusive than before? The Tale of a Historic Urban Park in Ankara, Turkey. URBAN DESIGN International, 20, 195-221. https://doi.org/10.1057/udi.2015.5

Büyüközkan, G., \& Görener, A. (2015). Evaluation of Product Development Partners Using an Integrated AHP-VIKOR Model. Kybernetes [Cybernetes], 44, 220-237. (In Czech) https://doi.org/10.1108/K-01-2014-0019

Ekdi, F. P., \& Çıracı, H. (2015). Really Public? Evaluating the Publicness of Public Spaces in Istanbul by Means of Fuzzy Logic Modelling. Journal of Urban Design, 20, 658-676. https://doi.org/10.1080/13574809.2015.1106919

ER, V. (2019). Investigating the Morphological Aspects of Public Spaces: The Case of Atakum Coastal Promenade in Samsun. Urban Design in City and Regional Planning, 1-257. 
Huang, J., Tzeng, G., \& Liu, H. (2009). A Revised VIKOR Model for Multiple Criteria Decision Making-The Perspective of Regret Theory. In Y. Shi, S. Wang, Y. Peng, J. Li, \& Y. Zeng (Eds), Cutting-Edge Research Topics on Multiple Criteria Decision Making. MCDM 2009. Communications in Computer and Information Science, vol 35. Heidelberg: Springer. https://doi.org/10.1007/978-3-642-02298-2_112

Georgiana, V., \& Damiano, C. (2013). Making the Publicness of Public Spaces Visible: from Space Syntax to the Star Model of Public Space. Visualizing Sustainability: Making the Invisible Visible (pp. 1-16). EAEA-11 Conference.

Kelleci, S. (2012). Investigating the Publicness of Administrative Spaces and a Case Study in Bakanliklar [Ministries] District: Ankara. Middle East Technical University, 1-162. (In Turkish)

Langstraat, F., \& Melik, R. V. (2013). Challenging the 'End of Public Space': A Comparative Analysis of Publicness in British and Dutch Urban Spaces. Journal of Urban Design, 18, 429-448. https://doi.org/10.1080/13574809.2013.800451

Memlük, N. O. (2012). Inclusivity of Public Space: Changing Inclusivity of an Urban Park, Gençlik Parki [Youth Park], Ankara. Middle East Technical University, 1-189. (In Turkish)

Pourjafar, M. R., Zangir, M. S., Moghadam, S. M., \& Farhani, R. (2018). Is There Any Room for Public? Democratic Evaluation of Publicness of Public Places. Journal of Urban and Environmental Engineering, 1-14. https://doi.org/10.4090/juee.2018.v12n1.026039

Varna, G., \& Tiesdell, S. (2010). Assessing the Publicness of Public Space: The Star Model of Publicness. Journal of Urban Design, 15, 575-598.

https://doi.org/10.1080/13574809.2010.502350 